\title{
A LEGITIMIDADE DO CONTROLE JURISDICIONAL DE POLÍTICAS PÚBLICAS DE SAÚDE E O FORNECIMENTO DE MEDICAMENTOS DE ALTO CUSTO SOB UMA PERSPECTIVA SUBSTANCIALISTA DO DIREITO
}

\author{
Leandro Correa de Oliveira ${ }^{53}$ \\ Adriano Rodrigo Reis ${ }^{54}$ \\ Recebido em: 03/05/2019 \\ Aprovado em: 19/09/2019
}

\begin{abstract}
RESUMO
Este trabalho objetiva analisar a legitimidade do controle jurisdicional das políticas públicas de saúde no Brasil questionando a atitude proativa do judiciário, sobretudo, do Supremo Tribunal Federal, no julgamento de demandas por medicamentos de alto custo em face do Estado, em sua matriz individual de atendimento. Diante do crescente fenômeno da judicialização da saúde, o problema é saber se a interferência do Tribunal nas políticas públicas de saúde, a qual, normalmente, tem adotado uma postura proativa (ativista), se legitima frente ao princípio democrático que constitui o Estado Social de Direito brasileiro estabelecido pela Constituição de 1988 e o princípio da separação dos poderes. A pesquisa desenvolve-se por meio de revisão bibliográfica, e utiliza-se de referenciais teóricos que, no âmbito da filosofia do direito e da teoria constitucional, adotam uma perspectiva substancialista do direito, como Mauro Cappelleti, Castanheira Neves, Ronald Dworkin e Luís Roberto Barroso. A conclusão aponta para o reconhecimento da legitimidade do controle jurisdicional das políticas públicas de saúde, em conformidade com a normativa constitucional e a realidade social, tendo em vista a necessidade de promoção dos avanços sociais que permanecem obstruídos no processo político majoritário.
\end{abstract}

Palavras-chave: Direito à saúde. Judicialização da saúde. Controle jurisdicional de políticas públicas.

\section{INTRODUÇÃO}

Nas últimas décadas, a nível global, tem-se observado uma acentuada transferência de poder de instituições representativas, como os Poderes Legislativo e Executivo, para os

\footnotetext{
${ }^{53}$ Doutor em Direito pela Faculdade Estácio de Sá. Mestre em Direito do Estado pela Universidade Federal do Paraná. Professor dos cursos de graduação e mestrado da Faculdade de Direito do Sul de Minas. Advogado.

${ }^{54}$ Mestrando em Direito pela Faculdade de Direito do Sul de Minas. Pós-Graduado em Direito Médico e da Saúde pela Faculdade de Direito de Varginha. Pós-Graduado em Direito Constitucional pela Faculdade Estácio de Sá.
} 
Tribunais, tanto domésticos, quanto supranacionais. Contemporaneamente, a concepção de supremacia constitucional é, em certa medida, distribuída por mais de 100 países pelo mundo. Tendência que tem se manifestado através do fenômeno da judicialização da política, vista como o recurso a tribunais e a meios judiciais para a discussão de importantes dilemas morais, problemas relacionados a políticas públicas e controvérsias políticas (HIRSCHL, 2006).

A judicialização da política, vista como o fenômeno da expansão global do Poder Judiciário, segundo C. Neal Tate e Torbjorn Vallinder (1995), se desenvolve de duas formas, não necessariamente em conjunto: a primeira, pelo processo no qual os tribunais e juízes passam a fazer ou a intervir na formulação de políticas públicas, que tradicionalmente eram feitas (ou deveriam ser feitas) por outras agências governamentais, sobretudo, legislativas e executivas, ou seja, os juízes "não-políticos" agindo como "políticos". A segunda forma é o processo pelo qual os fóruns de negociação e tomada de decisões não-judiciais (arenas políticas) passam a ser dominadas por regras e procedimentos quase-judiciais (legalistas), ou seja, "políticos" agindo como juízes "apolíticos" vinculados a regras procedimentais típicas dos processos judiciais.

No caso brasileiro, três grandes causas levaram à judicialização da política conforme aponta Luis Roberto Barroso (BARROSO, 2009): a primeira, relacionada ao processo de redemocratização do Brasil, que a partir de promulgação da Constituição Federal em 1988, fez com que o Poder Judiciário deixasse de ser um departamento técnico-especializado e se transformasse em um autêntico poder político, capaz de aplicar as normas constitucionais e demais leis, ainda que colidisse com os demais Poderes políticos; a segunda trata-se da "constitucionalização abrangente", que transferiu para o texto constitucional questões que, outrora, pertenciam somente ao processo político majoritário e às leis infraconstitucionais, o que, por consequência, aumentou a demanda por ações judiciais, haja vista que uma questão disciplinada na norma constitucional acaba se transformando em uma potencial pretensão jurídica; a terceira causa trata-se da própria estrutura do sistema brasileiro de controle de constitucionalidade, o qual é classificado como um sistema misto, compatibilizando características tanto do sistema americano, de controle incidental e difuso, quanto do sistema europeu, de controle por ação direta, realizado, originariamente, pelo Supremo Tribunal Federal quando do controle de constitucionalidade de uma lei.

Neste contexto, com base na perspectiva pós-positivista do direito, destacam-se duas posições com opiniões e formas distintas de analisar o fenômeno, as quais questionam sobre a legitimidade de atuação dos juízes e tribunais no âmbito político e os limites de tal atuação. São elas a corrente procedimentalista e a corrente substancialista do direito. Apesar de ambas 
reconhecerem no Poder Judiciário, sobretudo, na justiça constitucional, uma função estratégica nas Constituições do pós-guerra (STRECK, 2002. p.134), de um lado autores procedimentalistas, como por exemplo, Robert Alexy, Klaus Gunter, John Hart Ely e Jürgen Habermas - apesar de existirem diferenças dentro da mesma corrente (OLIVEIRA, 2010. p.85) - sustentam que, em uma sociedade pós-metafísica, não haveria mais princípios morais ou valores éticos capazes, suficientemente, de universalização em uma perspectiva substancial. De outro lado, na linha substancialista, se encontram autores como Ronald Dworkin, Mauro Cappelletti e Castanheira Neves, que propugnam haver não só a possibilidade, "mas também a necessidade de fundamentar adequadamente a existência de princípios morais e valores éticos substanciais” (SIMIONI. 2011).

A questão envolvendo o controle jurisdicional das políticas públicas, gira em torno dos limites e possibilidades dessa particular ação de controle, com destaque de velhos debates, como a separação e harmonia entre os poderes, e também novos, como a falta de aptidão funcional do Poder Judiciário para uma ação corretiva, ou até substitutiva no âmbito das políticas públicas (VALLE, 2016. p.32). E este último apontamento representa um parâmetro ou critério de grande relevância a ser observado pelos juízes e tribunais, quando do

julgamento de demandas judiciais por medicamentos de alto custo - é que a falta de capacidade técnica e de critérios adequados (como a medicina baseada em evidências) pode estar ensejando a prolação de decisões contrárias ao sistema de saúde e a ciência-médicofarmacêutica (SCHULZE, 2018. p.94)

Nos itens seguintes desta pesquisa, busca-se, portanto, aprofundar a discussão doutrinária sobre a legitimidade de atuação do Poder Judiciário ao interferir nas políticas públicas de saúde sob o ponto de vista dos paradigmas pós-positivistas do direito. Num primeiro momento é questionado os argumentos jusfilosóficos que sustentam a necessidade de uma intervenção judicial nas políticas públicas como um todo, destacando o posicionamento de autores que se apoiam numa perspectiva substancialista do direito. Em seguida, verificando o estado da arte das ações judiciais que trataram de demandas por medicamentos de alto custo, no âmbito do Supremo Tribunal Federal, busca-se identificar o posicionamento do referido Tribunal sobre o tema.

\section{A LEGITIMIDADE DO CONTROLE JURISDICIONAL DE POLÍTCAS PÚBLICAS: CONSTITUCIONALISMO VERSUS DEMOCRACIA?}


A Constituição significa mais do que o simples reflexo das condições fáticas de sua vigência, particularmente as forças sociais e políticas. A Constituição jurídica é condicionada reciprocamente pela realidade político-social, atribuindo sua vigência a uma situação regulada que pretende ser concretizada na realidade. Além desta realidade entendida como as condições naturais, técnicas, econômicas e sociais, deve-se levar em conta ainda o substrato espiritual que se consubstancia num determinado povo, ou seja, as concepções sociais concretas e seu baldrame axiológico. Neste sentido, já nos advertiu Konrad Hesse (HESSE, 1991) que "somente a Constituição que se vincule a uma situação histórica concreta e suas condicionantes, dotada de uma ordenação jurídica orientada pelos parâmetros da razão, pode, efetivamente, desenvolver-se".

Segundo Luís Roberto Barroso (BARROSO, 2006. p.1) a Constituição tem uma existência própria, autônoma, embora relativa, que advém de sua força normativa, pela qual ordena e conforma o contexto social e político. Existe assim entre a norma e a realidade uma tensão permanente, de onde derivam as possibilidades e os limites do Direito Constitucional, como forma de atuação social. Logo, o direito é concebido como um fenômeno social, e, em decorrência, a ciência jurídica é assumida como ciência dos problemas reais, práticos, voltada para resultados concretos e não para sistematizações conceituais abstratas.

Portanto, ao ser provocado o Poder Judiciário fica pressionado a responder aos reclamos da coletividade. E sem possuir respostas específicas para o estado de coisas inconstitucional produzido pela ineficácia de determinado direito fundamental, tende a aplicar as tradicionais formas de composição de conflito, manifestando-se, na visão de muitos, de forma ativista. Com efeito, Vanice Regina do Valle (VALLE, 2009) sustenta que existem críticas de que tal manifestação não tem se identificado com tanta frequência orientando-se à centralidade dos direitos fundamentais como fio condutor do raciocínio jurídico desenvolvido, mas tem se voltado a uma forte orientação pragmatista, articulada no centro de um discurso que busca ampliar as competências de conhecimento, e com isso, de criação de soluções normativas, caminhando para uma linha de fronteira com o governo dos juízes. A autora (VALLE, 2009. p.136) afirma ainda que

$\mathrm{O}$ ativismo brasileiro, portanto, centra-se no ativismo jurisdicional como mecanismo a assegurar a ampliação de competências (formal e normativa), caminhando para uma linha de fronteira com o governo dos juízes. Mas não qualquer juiz, já que a vinculatividade das decisões tornou-se um traço marcante do nosso sistema: por intermédio dela, reduz-se o espaço de atuação dos demais órgãos na dinâmica político-institucional interna ao judiciário. 
Neste sentido, Matthew M. Taylor (TAYLOR, 2007) sustenta que o Poder Judiciário possui um impacto significativo na elaboração das políticas públicas porque os tribunais influenciam a definição das alternativas pelo sistema político. No Brasil, considerando apenas as políticas implementadas pelo governo federal, “o sistema é altamente majoritário quando se trata do processo de deliberação de políticas públicas, mas tende para a forma consensual durante o processo de implementação das políticas". Isto se deve ao fato de que os tribunais acabam por ampliar o leque de atores que podem influenciar a implementação de políticas públicas, mesmo depois de serem aprovadas por amplas maiorias legislativas.

\subsection{Considerações sob uma perspectiva procedimentalista do direito}

Apesar da codificação dos direitos do homem por uma Constituição transformá-los em direitos fundamentais, o problema de sua institucionalização acaba sendo acrescido, agora, em razão de sua vinculatividade. Segundo Robert Alexy (ALEX, 2011. p. 49), os direitos fundamentais são caracterizados por quatro extremos: (1) o "grau de hierarquia extremo" na ordem hierárquica do direito, aliado à (2) "força de imposição extrema" - que impõe uma vinculação dos poderes políticos, sobretudo do Legislativo (dador de leis), e do próprio judiciário ao controla-la tornando os direitos fundamentais justiciáveis (uma das causas da judicialização da política) -, (3) os "objetivos extremamente importantes" e (4) a "medida máxima de necessidade de interpretação". Para o autor alemão, a ponderação de princípios é um problema da dogmática e, ao mesmo tempo, o fundamento para a abertura dos catálogos dos direitos fundamentais. Assim, por exemplo, o conteúdo rigoroso do direito à saúde, que deve ser garantido por medidas de política social e econômica, só pode ser comprovado por meio da ponderação.

Ao interpretar os direitos fundamentais, o Tribunal, transforma sua concepção sobre as coisas sociais e políticas em componentes da constituição, algo que o processo político ordinário, representado por uma maioria parlamentar simples, já não consegue obter. Os direitos do homem quando levados a sério, passando de um mero ideal, a algo real, através de sua institucionalização (direitos fundamentais), exigência oriunda do constitucionalismo, aparentemente, se convertem em um problema para a democracia (ALEX, 2011. p. 54). O juiz arbitral na luta pela interpretação dos direitos fundamentais não é o povo, mas o Tribunal Constitucional, o que, no caso brasileiro, coloca em risco o princípio democrático representativo estabelecido no parágrafo único da Constituição Federal Brasileira que afirma 
que "Todo o poder emana do povo, que o exerce por meio de representantes eleitos ou diretamente, nos termos desta Constituição".

A questão principal, portanto, é saber se o Poder Judiciário ao decidir e aplicar o direito no caso concreto - inclusive ponderando princípios através de um juízo de adequação e necessidade dos meios para atingir seus objetivos - tem o poder de escolher a aplicação de um princípio ao invés de outro, desde que justificada tal escolha por uma argumentação jurídica. Trata-se da existência de uma aparente tensão (ou apenas uma relação) entre o constitucionalismo e a democracia, entre, de um lado, a decisão jurídica baseada em uma argumentação de princípios constitucionais democráticos que valem independentemente da vontade das maiorias políticas, e de outro, a decisão política-legislativa baseada na representação democrática apoiada em eleições e reeleições políticas do legislativo e do governo executivo, tratando-se de princípios políticos que asseguram a equidade das políticas públicas do governo pela vontade das maiorias democráticas (SIMIONI, 2014. p.307).

Robert Alexy apresenta uma forma de estabelecer um equilíbrio discursivo entre a democracia e o constitucionalismo, entre a representação democrática e a representação argumentativa, através do "constitucionalismo discursivo" (ALEXY, 2008. p.163). Para ele a única maneira de reconciliar a jurisdição constitucional com a democracia é compreendê-la também como representação do povo. Com efeito, o conceito de democracia não pode se referir apenas a um procedimento de decisão centrado na eleição e na regra da maioria, um conceito baseado em um modelo puramente decisionista de democracia. É necessário também uma ideia de democracia baseada na argumentação, uma democracia deliberativa, na qual é possível institucionalizar o discurso como meio da tomada de decisão pública. Assim, a representação do povo pelo parlamento é, ao mesmo tempo, "volicional" ou "decisionista" e "argumentativa" ou "discursiva", enquanto que a representação do povo pelo tribunal constitucional é puramente argumentativa. Segundo o autor "A representação é - de outra forma como Kelsen propõe - mais que mera 'substituição' e, simultaneamente, mais que 'algo existencial', no sentido de algo meramente fático", conforme Carl Schmitt. Se existem argumentos válidos ou corretos, assim como pessoas racionais, então a razão e a correção serão institucionalizadas melhor com a jurisdição do que sem ela (ALEXY, 2008. p.164).

Segundo Fábio C. S. de Oliveira (OLIVEIRA, 2010. p.95), a perspectiva procedimentalista de Jürgen Habermas sustenta que o direito e a Democracia devem se ocupar dos processo de discussão pública, das formas dialógicas, dos meios e não dos fins. Dos mecanismos de debate e não do conteúdo ou do consenso que não é certo de ser atingido. Deixando, portanto, de se apoiar em uma concepção substancial que estipule resultados e 
postule um conteúdo irrecusável de origem naturalista ou suprapositivo, uma axiologia apriorística. A jurisdição constitucional deve apenas garantir as condições ideais do discurso a autonomia da formação de vontade - porque somente no discurso se torna possível à submissão da vigência social inquestionada do direito a pretensões de validade universais. Como a jurisdição não possui tais condições, consequentemente, não possui legitimidade para decidi-las (SIMIONI, 2014. p. 563), visto que, na medida em que "discursos políticos se estendem a negociações e à generalização moral de interesses, o procedimento democrático não pode mais extrair sua força legitimadora do acordo prévio de uma comunidade ética pressuposta, e sim de si mesmo" (HABERMAS, 1997. p. 353-354).

\subsection{Considerações sob uma perspectiva substancialista do direito}

Já para Ronald Dworkin, o direito não é apenas uma questão de fato, nem de interpretação semântica de textos, uma questão lógica de análise linguística, como defendido pelo positivismo jurídico (DWORKIN, 1999. p. 41). Para ele o direito é uma questão de justificação adequada - com convicções morais importantes - e de coerência. A prática do direito só pode ser interpretativa, sendo que, a escolha da interpretação adequada é uma escolha política, no sentido da coerência e integridade como projeto político de uma comunidade baseada em princípios, em convicções de moralidade política comuns.

Dividindo as normas jurídicas em regras e princípios, diferentemente de Alexy, Dworkin (DWORKIN, 2002) afirma que as regras são as normas jurídicas do direito positivo, ou seja, o direito positivo "escrito", enquanto que os princípios são os demais padrões normativos de moralidade que transcendem ao direito positivo, os quais são gênero das duas espécies: padrões morais e padrões políticos. É a partir destas premissas, analisando a relação entre os princípios e a democracia, o autor norte-americano aponta a existência de duas objeções à criação do direito pelos juízes (intérpretes) que apoiam a tese de que a decisão judicial deve ser subordinada à legislação, ou seja que a decisão judicial deve ser a menos original possível.

A primeira objeção defende que uma comunidade deve ser governada por pessoas eleitas pela maioria que lhes outorga a responsabilidade da criação das leis, e não por juízes que não foram eleitos, e, consequentemente, não são responsáveis perante o eleitorado (vontade da maioria). A segunda objeção afirma que se um juiz criar uma nova lei e aplica-la retroativamente, a parte perdedora será punida por ter violado um novo dever criado após o fato, o que leva à falta de segurança jurídica. Como, para Dworkin, os princípios ou são 
padrões morais, ou são padrões políticos (que podem ser consubstanciados em políticas públicas), tais objeções aplicar-se-iam de fato às decisões judiciais geradas por políticas e não às geradas por princípios.

Por um lado, na primeira objeção, ao pensarmos o direito como política - como um compromisso entre objetivos e finalidades individuais em busca do bem-estar da comunidade como um todo -, constatamos que o sistema político da democracia representativa funciona melhor que um sistema que permite que juízes não eleitos "estabeleçam compromissos entre os interessados concorrentes em suas salas de audiência" (DWORKIN, 2002. p.132), isto porque, as decisões sobre políticas devem ser operadas através de algum processo político criado para oferecer uma expressão exata dos diferentes interesses que devem ser levados em consideração. Por outro lado, na segunda objeção, devemos concordar que é errado sacrificar os direitos de um homem inocente em nome de algum novo dever, criado depois do fato, ou seja, tomar os bens de um indivíduo e dá-los a outro, somente com o intuito de melhorar a eficiência econômica global.

Contudo, esclarece Dworkin, que os argumentos apresentados não constituirão objeções a uma decisão jurídica, caso seja esta justificada, coerentemente, não mais em padrões políticos (objetivos políticos), mas sim, em princípios, como convicções morais importantes para determinada comunidade. Primeiro porque um argumento de princípio estabelece alguma vantagem apresentada por quem reivindica o direito que o argumento descreve, uma vantagem cuja natureza torna irrelevantes e sutis discriminações de qualquer argumento de política que a ela se pudesse opor. Portanto, um juiz que não é pressionado pelas demandas da maioria política, terá uma melhor posição para avaliar o argumento. Segundo porque, se um demandante tem um direito contra o demandado, então este tem um dever correspondente, e é este dever, e não um novo dever produzido pelo magistrado, que justifica a sentença contrária a ele. Um argumento de princípio nos leva a considerar a reivindicação do demandado de que é injusto surpreendê-lo com a decisão (DWORKIN, 2002. p.135).

Se a reivindicação do demandante for duvidosa, o juiz ou tribunal poderá até surpreender qualquer uma das partes, porque ao decidir que o argumento do demandante é o mais forte, depois de sopesadas as razões de ambas as partes, também terá decidido que as expectativas do demandante eram mais justificadas. Uma atuação inibida do Judiciário pode gerar tantos males ou prejuízos quanto um desmedido ativismo. O judicial self-restraint não é uma fórmula ótima, podendo expressar uma omissão, que o judiciário ficou inerte quando tinha a obrigação de agir, o que possibilita danos ao indivíduo e à coletividade. O direito de 
infringir a vontade da maioria não depende do subjetivismo, do voluntarismo, da opinião de cada um, mas sim diz respeito a direitos fundamentais, como a liberdade de expressão, direitos previstos na Constituição, nas Declarações de Direitos, enunciados, de uma maneira mais essencial ou comum, por princípios (OLIVEIRA, 2010. p.126).

Mauro Cappelletti (CAPPELLETTI, 1999), adotando a perspectiva substancialista do direito, afirma que o verdadeiro problema envolvendo a "criatividade jurisprudencial" é a identificação do grau de criatividade dos modos, limites e aceitabilidade da criação do direito pelos juízes, a criatividade judicial. É descobrir os limites do papel do juiz em face do papel do legislador. Os limites processuais envolvem a própria "natureza" do processo judiciário, funcionando como pressuposto de existência do mesmo, enquanto os limites substanciais variam conforme a época e lugar, e não constituem requisito essencial da natureza jurisdicional de uma decisão ou processo judicial.

$\mathrm{Na}$ prática, as decisões judiciais podem ser baseadas mais do que na lei, também na equidade ou outros valores. Com a ressalva de que, uma decisão baseada na equidade terá um espaço de escolha mais amplo, produzindo um maior grau de criatividade por parte do intérprete. O juiz, vinculado à lei (e aos precedentes judiciais) tem o dever mínimo de apoiar sua própria argumentação em tal direito posto e não apenas na equidade. Entretanto, toda situação de fato é nova, podendo a decisão, conforme o caso concreto, distinguir quanto aos precedentes e, até mesmo, argumentar a contrário do direito legislativo.

Diante desta tensão existe uma fronteira do bom senso, visto que, as palavras têm normalmente um significado tão geralmente aceito que até o juiz mais criativo e sem preconceitos teria dificuldade de ignorá-los. A diferença fundamental, moral e estrutural da função jurisdicional em relação à legislativa não são os limites substanciais, mas sim, os limites processuais. Apesar dos juízes interpretarem, criando o direito, isto não quer dizer que eles sejam legisladores. O que faz um juiz ser um juiz não é a sua criatividade, seu poder de criação do direito, mas sim, a conexão com as partes e o caso concreto, a atitude de imparcialidade e independência com relação a pressões externas (políticas) e o direito das partes serem ouvidas - o princípio do contraditório (CAPPELLETTI, 1999. p.73-81).

O jusfilósofo italiano apresenta quatro justificativas ao problema da legitimidade democrática do "direito jurisprudencial", que afirma que os juízes seriam menos obrigados a "prestar contas" de suas decisões à maioria, visto que não foram eleitos por seus votos. Segundo ele (1) os poderes políticos, executivo e legislativo, nem sempre tomam decisões que representam a vontade da maioria, pois são influenciados muitas vezes pelo poder econômico e por grupos de interesses específicos; (2) o judiciário também pode possuir certa carga de 
representatividade, visto que, normalmente os membros da corte são nomeados pelo presidente com o consentimento do parlamento - o que não significa que a corte seja mero "agente de aliança” política -, bem como, suas decisões costumam ser abertas ao público (por exemplo, no Brasil, com a TV Justiça) e justificadas de forma presumidamente arrazoada e lógica, tornando os juízes mais responsáveis que outros entes e organismos administrativos; (3) os tribunais podem dar contribuições à representatividade geral do sistema, permitindo o acesso ao processo judicial, dando proteção a grupos marginais (raciais, religiosos, econômicos de baixa renda) que não teriam acesso ao processo político; (4) por fim, o processo jurisdicional é mais participativo do que outros, levando-se em conta que a capacidade de acessibilidade dos tribunais é superior à de outros órgãos do governo, pois apresentada a demanda ao juiz, este não poderá deixar de dar uma resposta, em obediência ao princípio da inafastabilidade da tutela jurisdicional (CAPPELLETTI, 1999. p. 92-107).

Segundo Rafael Lazzaroto Simioni (SIMIONI, 2014. p.474), na perspectiva jurisprudencialista do direito de Castanheira Neves, a decisão jurídica não necessita de legitimidade política porque o jurídico não pode ser reduzido ao político. Formalmente, a decisão jurídica não deve subtrair a competência do legislador na criação de normas como instrumento das políticas públicas de governo, bem como, materialmente, a realização do direito pela decisão jurídica é um compromisso de concretização da intencionalidade normativa do direito que existe antes da decisão.

O autor português, ao analisar o problema da racionalidade jurídica, destaca dois fatores determinantes na sua tarefa de realização do direito: (1) a concepção do direito pressuposta pelo pensamento jurídico e (2) a atitude intencional desse pensamento perante o direito. O pensamento jurídico é sensível ao contexto cultural global em relação aos objetivos da práxis e aos modelos de racionalidade dominantes, fazendo com que a intenção de fazer assimilar pelo pensamento jurídico esses modelos determine a concepção do direito - como sistema axiológico, sistema regulamentar, estratégico, social, etc (NEVES, 1993. p.49).

Quanto às atitudes intencionais do pensamento jurídico destaca três tipos: a intenção teorética, a intenção instrumental e a intenção normativa. Ao criticar a intenção teorética, afirma que, na sociedade contemporânea, a racionalidade jurídica não pode ter somente uma índole formal e lógica, como resultado de uma perspectivação do direito como um objeto dogmático-conceitual para uma intencionalidade meramente teorética. O pensamento jurídico não pode ser dogmático-logicamente determinista na sua tarefa de realização do direito, haja vista que tal realização exige uma mediação normativamente constitutiva. Também não pode aceitar a racionalidade teorética-explicativa proposta pelo realismo jurídico, que no fundo, 
não oferece uma racionalidade jurídica, mas, sim, uma racionalidade de um pensamento psicológico e sociológico, substituindo a fundamentação normativa por uma explicação empírica (uma motivação psico-sociológica). No tocante a intenção instrumental, o problema é que o direito compreender-se-ia como uma "estratégia político-social funcional e finalísticamente programada", a decisão concreta como uma tática de realização ou execução consequencial, e a própria função judicial como uma "instituição funcionalmente adequada a essa estratégia/tática" (NEVES, 1993. p.56).

Em um Estado Democrático de Direito, o direito não pode ser concebido como um mero instrumento para o alcance de objetivos estratégicos mesmo que sob a justificativa do "bem comum", conforme a "vontade do povo". O êxito dos fins não pode ser a prioridade acima da consideração de valores materiais e regras formais. Para Castanheira Neves, a questão da decisão jurídica é de mediação entre o problema e o sistema jurídico, tratando-se de uma questão essencialmente jurídica e não política, de uma intencionalidade normativa com caráter axiológico que transcende uma fundamentação política. A concepção de que o direito deve seu fundamento à política é uma armadilha do positivismo jurídico, que considerava o direito não mais que uma expressão normativa do poder político. Comentando sobre o autor português, Rafael Lazarotto Simioni afirma que "a pergunta pela legitimidade política das decisões jurídicas deve ser substituída pela pergunta pela legitimidade ética das decisões jurídicas em relação à consciência jurídica geral da comunidade” (SIMIONI, 2014. p.476).

Não obstante variarem as considerações sobre a questão da legitimidade política das decisões jurídicas conforme os diferentes pontos de vista dos jusfilósofos da corrente substancialista do direito, conforme foi apresentado, constata-se que ambos defendem uma postura assertiva por parte dos juízes, na busca da afirmação dos direitos fundamentais como genuínas conquistas históricas da cidadania. No fundo acreditam em padrões morais ou éticos (suprapositivos) conquistados historicamente que, para além do direito positivado, podem ser encontrados em determinada comunidade, servindo de base para a escolha ou interpretação mais adequada da norma pelo julgador no momento de sua decisão no caso concreto.

Desta forma, para esta corrente de pensamento, é justificável a atuação dos juízes e tribunais quando solicitados a pronunciar e interpretar normas que envolvam direitos fundamentais, mesmo quando suas decisões caminhem em sentido contrário à vontade política do governo executivo e do poder legislativo, os quais atuam sob uma lógica estratégica, e que representariam, em tese, a maioria da vontade popular. 


\section{A JUDICIALIZAÇÃO DOS MEDICAMENTOS DE ALTO CUSTO}

A judicialização da saúde no Brasil diz respeito ao aumento de demandas judiciais envolvendo o direito à saúde, e faz parte de um contexto maior relacionado ao fenômeno da judicialização da política, como já exposto anteriormente. Já a “judicialização dos medicamentos de alto custo" é uma das maneiras como a judicialização da saúde vem sendo desenvolvida pelo judiciário brasileiro, isto porque, existem outros diversos tipos de prestações materiais estatais que também são objeto de demandas judiciais envolvendo o direito à saúde, como por exemplo, tratamentos médicos, vagas em leitos de hospitais e UTIs, transplantes de órgãos, chegando, até mesmo, ao pedido de fraudas.

Diante desta variedade de tipos de prestações materiais estatais de assistência à saúde que normalmente são objeto de diversas demandas judiciais, optamos por restringir a pesquisa aos pedidos (individuais) por medicamentos de alto custo. Apesar de não abordar o problema da judicialização da saúde como um todo, tal delimitação tem a vantagem de uma análise mais pormenorizada da lógica argumentativa desenvolvida pelos ministros do STF em suas decisões, isto é, de uma análise mais específica dos fundamentos desenvolvidos sobre o tema, durante todo o histórico jurisprudencial do STF.

Através da utilização da ferramenta de pesquisa jurisprudencial disponível no portal do Supremo Tribunal Federal ${ }^{55}$, atualizada até o dia 20 de dezembro de 2018. Ao inserirmos as palavras-chaves: "remédios" - obtivemos 50 acórdãos e 685 decisões monocráticas; "medicamento" - 283 acórdãos e 2945 decisões monocráticas; "tratamento" - 1432 acórdãos e 15503 decisões monocráticas; "alto custo" - 27 acórdãos e 582 decisões monocráticas; "HIV" - 20 acórdãos e 179 decisões monocráticas; e "cirurgia" - 80 acórdãos e 997 decisões monocráticas. Dentre todos os acórdãos, selecionamos 112 para serem analisados.

No âmbito do Supremo Tribunal Federal, foi no início da década de 1990 que as demandas por medicamentos começaram a aparecer com força, sobretudo em pedidos de medicamentos para tratamento do HIV/AIDS. Foi um momento de construção dos primeiros critérios e parâmetros sobre o tema, os quais tem sido motivo de discussão, até os dias de hoje, na jurisprudência e na doutrina. A partir dos anos seguintes, as demandas passaram a incluir outros tipos de medicamentos, para tratamento de outras doenças como o câncer e

\footnotetext{
55 Disponível em <http://www.stf.jus.br/portal/jurisprudencia/pesquisarJurisprudencia.asp>. Acesso em: $20 \mathrm{dez}$ 2018.
} 
doenças raras, bem como, outras formas de assistência estatal à saúde, como pedidos por tratamentos diversos, insumos, cirurgias, vagas em leitos de UTI, entre outros.

Através da análise realizada, verificamos que na jurisprudência do Supremo Tribunal Federal dentre os precedente mais remotos sobre o tema da judicialização da saúde, podemos destacar a decisão monocrática na Suspensão de Segurança no 659/RS, de relatoria do Min. Carlos Velloso, de 22 de julho de $1994^{56}$ julgada em conjunto com a SS 674/RS. O caso envolveu uma demanda judicial, deferida pelo Tribunal de Justiça do estado do Rio Grande do Sul no sentido de compelir o órgão de saúde estadual a colocar a disposição do impetrante, um menor de 18 anos, cerca de duzentos mil dólares, necessários para a realização de uma cirurgia na NASA, a agencia espacial norte-americana. A cirurgia tinha por objetivo "a tentativa de afastar a tetraplegia do Impetrante, decorrente de um disparo acidental de arma de fogo".

Ainda no ano de 1994, identificamos a existência daquele que pode ser o caso mais remoto a tratar de pedido de fornecimento de medicamento pelo Estado no âmbito do STF. Refere-se a pedido de Suspensão de Segurança $n^{\circ} 720 /$ RJ $^{57}$ contra liminar concedida pelo Tribunal de Justiça do Estado do Rio de Janeiro em face daquele mesmo Estado para que se fornecesse determinada quantidade de medicamento a paciente, durante o período de seis meses, ou a quantia correspondente ao respectivo preço, em dólares, para aquisição no exterior. O pedido, no entanto, foi indeferido, após sopesados, conforme a decisão, “os riscos opostos, da lesão à economia pública de um lado, e do perigo de vida, a que, de outro, está sujeito o impetrante, para pronunciar-se pela predominância desse último valor". O que, em certa medida, demonstrou o posicionamento do tribunal que viria a prevalecer até os dias atuais, reconhecendo a obrigatoriedade do Estado em prestar medicamentos levando-se em conta tão-somente uma ponderação de valores ou princípios: de um lado o direito à vida do postulante e, de outro, questões econômico-financeiras.

Posteriormente, em 1998, em decisão monocrática proferida pelo Ministro Marco Aurélio, foi negado o pedido feito no Agravo de Instrumento $\mathrm{n}^{\mathrm{o}} 232.469 / \mathrm{RS}^{58}$ interposto pelo município de Porto Alegre contra acórdão proferido pelo Tribunal de Justiça do Estado do Rio Grande do Sul que determinou aquele município a entrega de medicamentos para tratamento de pessoa portadora do vírus HIV a qual não possuía recursos financeiros para adquiri-los. Os

\footnotetext{
${ }^{56}$ STF. Suspensão de Segurança n ${ }^{\circ}$ 659/RS, relator: Min. Carlos Velloso, julgamento em 22 de julho de 1994, DJ 03/08/1994.

${ }^{57}$ STF. Suspensão de Segurança n ${ }^{\circ}$ 720/RJ, relator: Min. Octavio Gallotti, decisão da Presidência, julgamento em 06/12/1994, DJ 13/12/1994.

${ }^{58}$ STF. Agravo de Instrumento 232469/ RS, Relator: Min. Marco Aurélio, decisão monocrática, julgamento em 12 de dezembro de 1998, DJ 23/02/1999.
} 
argumentos apresentados pelo município afirmavam que os preceitos dispostos nos artigos 196, 197 e 198 da Constituição Federal de 1988, seriam normas de conteúdo programático dependentes de regulamentação "não implicando a transferência, àquele ente da federação, da obrigação de fornecer os medicamentos especiais e excepcionais pleiteados". Destacou também que, em face da autonomia do município, não se poderia impor a ele a obrigação sem que antes fossem estabelecidas as formas de repasse dos recursos.

Contudo, entendeu o ministro Marco Aurélio que o preceito do artigo 196 da Constituição é norma de eficácia imediata, e que a referência “a 'Estado' mostra-se abrangente, a alcançar a União Federal, os Estados propriamente ditos, o Distrito Federal e os Municípios”. Acrescentou que o município de Porto Alegre possuía responsabilidade previstas em diplomas específicos, segundo o ministro, "os convênios celebrados no sentido da implantação do Sistema Único de Saúde, devendo receber, para tanto, verbas do Estado". Destacou ainda que "a falta de regulamentação municipal para custeio da distribuição não impede fique assentada a responsabilidade do Município”.

Neste caso, apesar de tratar-se do proferimento de uma decisão monocrática, o reconhecimento do conteúdo da norma disposta no artigo 196 da Constituição Federal como norma de eficácia imediata e aplicabilidade direta, e não como norma meramente programática, bem como, o reconhecimento do direito a medicamentos ligado ao direito à vida como um direito subjetivo em face do Estado, serão, em outras decisões posteriores, os principais argumentos utilizados pelos ministros para se obrigar o Estado a fornecer medicamentos de alto custo pleiteados individualmente.

Isto fica claro também no julgamento do paradigmático Recurso Extraordinário $\mathrm{n}^{\circ}$ 271.286/RS na decisão monocrática proferida pelo Ministro Celso de Mello em 02/08/2000 59 e no acórdão do agravo interposto pelo Município de Porto alegre no mesmo recurso (271.286-8/RS), julgado em 12/09/2000 ${ }^{60}$ pela segunda turma do STF, o qual foi negado provimento. Referido recurso foi interposto pelo Estado do Rio Grande do Sul e pelo município de Porto Alegre, buscando reformar a decisão do Tribunal de Justiça daquele Estado que havia reconhecido a obrigação dos recorrentes em fornecerem, gratuitamente, medicamentos necessários ao tratamento da AIDS, nos casos que envolviam pacientes destituídos de recursos financeiros suficientes e que eram portadores do vírus HIV.

\footnotetext{
${ }^{59}$ STF. Recurso Extraordinário 271286/RS, Relator: Min. Celso de Mello, decisão monocrática, julgamento em 02 de agosto de 2000, DJ 23/08/2000.

${ }^{60}$ STF. Recurso Extraordinário 271286-8/RS, Relator: Min. Celso de Mello, Acórdão proferido pela $2^{\mathrm{a}}$ turma em 12 de setembro de 2000, DJ 24/11/2000.
} 
Os argumentos apresentados pelos recorrentes no referido Recurso Extraordinário buscaram sustentar que o acórdão, além de ir contra ao art. 37, inciso XXI da Constituição Federal (exigência de licitação), teria desrespeitado o princípio da legalidade, pois teria violado “o acórdão recorrido o art. 167, incisos I e VI, da Constituição Federal, que veda o início de programas ou projetos não incluídos na lei orçamentária anual”, isto porque, conforme determinação constitucional (art. 165, $\S 5^{\circ}$, inciso III da Constituição Federal) "são de iniciativa do Poder Executivo as leis que estabelecem os orçamentos anuais e é nessa lei que deverá ser previsto o orçamento da seguridade social”. Acrescentou, ainda, que a decisão agravada "deixou de observar a repartição de competência para operacionalização dos serviços de saúde, como forma de gestão financeira dos recursos", afrontando o princípio federativo da separação dos poderes, bem como o art. 198 e seu parágrafo único, da Constituição Federal.

O tema das políticas públicas de saúde, em sua matriz "coletiva", foi tratado no julgamento da $\operatorname{ADPF} \mathrm{n}^{\mathrm{o}} 45$ (não como questão principal), na qual se discutiu sobre a legitimidade constitucional do controle e intervenção do Poder Judiciário em temas relacionados à implementação de políticas públicas, especialmente aquelas relacionadas às ações e serviços de saúde, onde se sustentou a tese do "mínimo existencial" em detrimento da "reserva do possível" e dos limites financeiros do Estado. No despacho emanado pelo Ministro Celso de Mello é afirmado que a atribuição de julgar a ADPF 45 conferida ao STF evidencia a "dimensão política da jurisdição constitucional" conferida àquele tribunal, que possui o encargo de tornar efetivos os direitos econômicos, socais e culturais.

O Ministro reconheceu que não é atribuição ordinária do Poder Judiciário a formulação e implementação de políticas públicas, contudo, excepcionalmente, terá esta atribuição, o judiciário, quando os órgãos estatais competentes descumprirem os encargos político-jurídicos que possam comprometer a eficácia e a integridade dos direitos individuais e/ou coletivos, mesmo que derivado de cláusulas revestidas de conteúdo programático. Neste caso, considerando não ser absoluta a liberdade de conformação do legislador, nem a de atuação do Poder executivo nas questões envolvendo a formulação e execução de políticas públicas, na opinião do Ministro, se justifica a intervenção do Poder Judiciário se tais poderes políticos "agirem de modo irrazoável ou precederem com a clara intenção de neutralizar" a eficácia dos direitos sociais afetando o "mínimo existencial".

A regra, portanto, é que a implementação e execução de políticas públicas (entre elas as de saúde pública) é atribuição precípua do Poder Executivo, que o faz, tomado decisões alocativas dentro de sua margem discricionária (e não arbitrária), segundo critérios 
consistentes de razoabilidade, "a fim de cumprir o dever de adotar a solução mais adequada à satisfação da finalidade legal” (MELLO, 2006. p.916), isto é, através de um juízo de conveniência e oportunidade, o qual compõe o "mérito" do ato administrativo praticado. Neste sentido, José dos Santos Carvalho Filho (CARVALHO FILHO, 2016, p.110) afirma que:

a conveniência e oportunidade "são os elementos nucleares do poder discricionário. A primeira indica em que condições vai se conduzir o agente; a segunda diz respeito ao momento em que a atividade deve ser produzida. Registre-se, porém, que essa liberdade de escolha tem que se conformar com o fim colimado na lei, pena de não ser atendido o objetivo público da ação administrativa.

Reconhecendo os problemas gerados pelo crescimento do número de demandas judiciais por medicamentos de alto custo, e buscando controlá-las de forma a diminuir seu impacto negativo no sistema público de saúde, o STF, em 2009, realizou audiência pública sobre a judicialização da saúde, presidida pelo Ministro Gilmar Mendes, onde participaram especialistas da área de saúde e do direito, tendo como casos emblemáticos, naquele momento, as Suspensões de Tutela Antecipada (STA) nº 175 e 178. Já no ano seguinte, foi aprovada a Recomendação 31 pelo Conselho Nacional de Justiça (CNJ), a qual estabeleceu diretrizes aos magistrados no tocante às demandas judiciais que tratam de assistência à saúde, buscando, em certa medida, fortalecer a capacidade institucional dos tribunais.

Comentando sobre estas duas medidas adotadas pelo STF Daniel W. Liang Wang (WANG, 2013) sustenta que as duas respostas dadas pelo Tribunal compartilham a premissa de que tribunais bem informados, treinados e assistidos, tomando decisões restritas a determinados critérios, podem superar a falta de capacidade institucional e, portanto, decidir sobre a alocação de recursos públicos de saúde. Contudo, ressalta o autor que, nos casos envolvendo a judicialização da saúde, a Suprema Corte não tem agido de forma justa e racional como deveria.

Para o autor, a resposta mais adequada, neste caso, foi dada pelo Legislativo quando promulgou a Lei Federal 12.401/2011, que criou uma nova instituição responsável pelo sistema de avaliação das tecnologias de saúde e um novo procedimento administrativo para decidir sobre a incorporação de tratamentos no sistema público de saúde, isto porque, a resposta legislativa buscou tornar o procedimento administrativo mais imparcial, robusto e transparente, a fim de convencer os tribunais a respeitarem mais aquilo que foi decidido no âmbito administrativo.

Atualmente, o Recurso Extraordinário $\mathrm{n}^{\circ} 566.471 / / \mathrm{RN}$ tem servido como o último paradigma jurisprudencial da Suprema Corte a tratar do tema. Este recurso teve repercussão 
geral reconhecida em 03 de dezembro de 2007 e se encontra, ainda, em julgamento, desde a última seção de julgamento realizada no dia 28 de setembro de 2016, onde já votaram três Ministros.

\section{CONSIDERAÇÕES FINAIS}

Os argumentos apresentados nesta pesquisa, em relação aos juristas que se filiam à corrente substancialista, defendem a legitimidade democrática da atuação do Poder Judiciário em questões tradicionalmente de competência dos poderes políticos - legislativo e executivo - quando esta atuação se referir à proteção e reconhecimento de direitos fundamentais. Não obstante os Magistrados não terem sido eleitos pela vontade da maioria do "povo", e, muitas das vezes, tomarem decisões contra o interesse político - que age estrategicamente visando objetivos mutáveis, segundo a vontade ou discricionariedade do governante ou partido político que está no poder e que pode mudar a qualquer momento, em uma nova eleição para a corrente substancialista, somente através do Poder Judiciário é que os padrões morais e éticos, ou os princípios suprapositivos vistos como conquistas históricas, para além do direito positivo, podem ser protegidos, garantidos e reconhecidos, servindo de base para a escolha ou interpretação mais adequada da norma pelo julgador no momento de sua decisão no caso concreto.

Considerando o histórico jurisprudencial analisado, verifica-se que os ministros do Supremo Tribunal Federal ao se pronunciaram sobre a questão do fornecimento de medicamentos de alto custo, definiram requisitos nos quais qualquer pessoa necessitada de medicamentos ou tratamentos médicos considerados de alto custo, que não tenha condições financeiras de arcar com suas despesas, desde que comprove tal situação, bem como comprove a eficácia e não existência de substituto disponível pelos órgãos públicos, terá a possibilidade de reconhecimento de seu direito pleiteado judicialmente, independentemente de seu custo.

Tal posicionamento acerca do direito a saúde, sobretudo, nos casos envolvendo o fornecimento de medicamentos de alto custo, demonstra a tendência dos ministros em reconhecer o direito à saúde, neste caso, como um direito subjetivo de cunho individual, mesmo contra o interesse político do Estado, conforme a vontade dos órgãos componentes dos Poderes Executivo e Legislativo, que por sua vez, representa a vontade majoritária, e apresenta argumentos como a falta ou a escassez de recursos orçamentários, coadunando-se, 
portanto, com o posicionamento da corrente substancialista do direito, que afirma a legitimidade do judiciário em decidir tais questões.

\section{REFERÊNCIAS}

Judicialização, ativismo judicial e legitimidade democrática. Revista de Direito do Estado, $\mathrm{n}^{\mathrm{o}}$ 13, p. 71-91, jan./mar. 2009. Disponível em: $<$ http://www.oab.org.br/editora/revista/users/revista/1235066670174218181901.pdf $>$. Acesso em: $21 / 02 / 2018$.

. O Império do Direito. Martins Fontes. São Paulo, 1999.

. Regras, princípios e políticas públicas em Ronald Dworkin: a questão da legitimidade democrática das decisões jurídicas. Revista direito Mackenzie. v. 5, n. 1 (2011). p. 203-218. Disponível em: <http://editorarevistas. mackenzie.br/index.php/rmd/article/view/4756/3658>. Acesso em: 10/12/2018.

ALEXY, Robert. Constitucionalismo discursivo. Org./trad. Luís Afonso Heck, 3. ed. Porto Alegre: Livraria do Advogado Editora, 2011.

BARROSO. Luís Roberto. O Direito Constitucional e a efetividade de suas normas. Limites e possibilidades da Constituição Brasileira. 8. ed. Rio de Janeiro: Renovar. 2006. CANOTILHO. J. J. Gomes. Direito Constitucional e Teoria da Constituição. 7. ed. Coimbra: Almedina, 2000.

CAPPELLETTI, Mauro. Juízes Legisladores? Sérgio Antonio Fabris Editor. Porto Alegre/RS, 1999.

CARVALHO FILHO, José dos Santos. Manual de direito administrativo. 30. ed. rev. São Paulo: Atlas, 2016.

DWORKIN, Ronald. Levando os Direitos a sério. Martins Fontes. São Paulo, 2002.

HABERMAS, Jürgen. Direito e Democracia. Entre facticidade e validade. VI. Tempo Brasileiro, Rio de Janeiro, 1997.

HESSE, Konrad. A força normativa da Constituição. Trad. Gilmar Ferreira Mendes. Porto Alegre: Sérgio Fabris Editor, 1991. [orig. Die normative Kraft der Verfassung, J.C.B. Mohr (Paul Siebeck), Tübingen]. 
HIRSCHL, Ran. The new constitutionalism and the judicialization of pure politics worldwide. Fordham Law Review, v. 75, n. 2, 2006. Traduzido por Diego Werneck Arguelhes e Pedro Jimenez Cantisano. In Revista de Direito Administrativo. FGV. Disponível em: $<$ http://bibliotecadigital.fgv.br/ojs/index.php/rda/article/view/7533/ 6027>. Acesso em 21/02/2018.

MELlO, Celso Antonio Bandeira de. Curso de Direito administrativo. 20. ed. São Paulo: Malheiros, 2006.

NEVES, Antônio Castanheira. Metodologia Jurídica. Problemas Fundamentais. Coimbra Editora. 1993.

OLIVEIRA, Fabio Corrêa Souza de Oliveira. Morte e Vida da Constituição Dirigente. Lumens Juris. RJ 2010.

SIMIONI. Rafael Lazzaroto. Curso de Hermenêutica Jurídica Contemporânea. Do Positivismo Clássico ao Pós-positivismo Jurídico. Juruá Editora. Curitiba, 2014.

SCHULZE, Clenio Jair. A judicialização da saúde no século XXI. Porto Alegre: Verbo Jurídico, 2018.

STRECK, Lenio Luiz. Jurisdição Constitucional e Hermenêutica. Uma nova Crítica do Direito. Livraria do advogado. Porto Alegre/RS, 2002.

TAYLOR, Matthew M.. O judiciário e as políticas públicas no Brasil. Dados-Revista de Ciências Sociais, Rio de Janeiro, v.50, n.2, p.229-257, 2007. Disponível em: $<$ http://www.scielo.br/scielo.php?script=sci_arttext\&pid=S001152582007000200001\&lng=en \&nrm=iso>. Acesso em: 03 Mai 2019.

TATE, C. Neal e VALLINDER, Torbjorn. The Global Expansion of Judicial Power. New York. New York University Press,1995.

VALle, Vanice R. L. Políticas Públicas, Direitos Fundamentais e Controle Judicial. Belo Horizonte: Fórum, 2016.

WANG, Daniel W. Liang. Courts as healthcare policy-makers: the problem, the responses to the problem and problems in the responses. São Paulo Law School of 
Fundação Getulio Vargas - DIREITO GV Research Paper Series - Legal Studies, Paper n. 75, 2013.

\title{
THE LEGITIMACY OF JURISDICTIONAL CONTROL OF PUBLIC HEALTH POLICIES AND THE SUPPLY OF HIGH COST MEDICINES UNDER A SUBSTANTIAL PERSPECTIVE OF THE LAW
}

\begin{abstract}
This paper aims to analyze the legitimacy of the jurisdictional control of public health policies in Brazil, questioning the proactive attitude of the judiciary, especially the Federal Supreme Court, in the judgment of demands for high cost drugs against the State in its individual care unit . Faced with the growing phenomenon of health judicialization, the problem is whether the Court's interference in public health policies, which has usually adopted a proactive (activist) stance, legitimates itself against the democratic principle that constitutes the Social State of Brazilian law established by the 1988 Constitution and the principle of separation of powers. The research is developed through a bibliographical review, using theoretical references that, within the scope of the philosophy of law and constitutional theory, adopt a substantialist perspective of law, such as Mauro Cappelleti, Castanheira Neves, Ronald Dworkin and Luís Roberto Barroso. The conclusion points to the recognition of the legitimacy of judicial control of public health policies, in accordance with constitutional norms and social reality, in view of the need to promote social advances that remain obstructed in the majority political process.
\end{abstract}

Keywords: Palavras-chave: Right to health. Judicialization of health. Judicial control of public policies. 